\title{
A survey of potential and previous cataract-surgery patients: what the ophthalmologist should know
}

\author{
This article was published in the following Dove Press journal: \\ Clinical Ophthalmology \\ 25 August 2014 \\ Number of times this article has been viewed
}

\author{
Bonnie An Henderson' \\ Kerry Solomon ${ }^{2}$ \\ Samuel Masket ${ }^{3}$ \\ Richard Potvin ${ }^{4}$ \\ Edward J Holland ${ }^{5}$ \\ Robert Cionni ${ }^{6}$ \\ Helga Sandoval ${ }^{2}$ \\ 'Ophthalmic Consultants of Boston, \\ Boston, MA, ${ }^{2}$ Carolina Eyecare \\ Research Institute, Carolina Eyecare \\ Physicians, Mount Pleasant, SC, \\ ${ }^{3}$ Advanced Vision Care, Los Angeles, \\ CA, ${ }^{4}$ Science in Vision, Akron, NY, \\ ${ }^{5}$ Cincinnati Eye Institute, Cincinnati, \\ $\mathrm{OH},{ }^{6}$ Eye Institute of Utah, Salt Lake \\ City, UT, USA
}

\begin{abstract}
Objective: This study utilized a phone survey to characterize patient perceptions of cataract surgery and the manner in which the ophthalmologist contributes to the patient's understanding in electing cataract surgery.
\end{abstract}

Patients and methods: Calls were made from a randomized membership list of the American Association of Retired Persons until 1,000 respondents 50 years of age or older had been recruited. Three groups were recruited: persons with no prior diagnosis of cataracts, persons diagnosed with cataracts but who had not had surgery, and persons who had had cataract surgery on both eyes within the past 5 years. A series of fixed-choice and open-ended questions was then presented to qualified participants. Questions related to vision, quality of life, and the understanding and perceptions of cataract surgery.

Results: Two-thirds of respondents reported having frequent eye examinations. More than half indicated that they had discussed cataract surgery with an eye doctor, most often with an ophthalmologist. They reported that the benefits of surgery were most often mentioned (68\%), but lens options were infrequently mentioned (39\%). Of those who had had surgery, $81 \%$ elected to do so on the advice of their health care professional. About $85 \%$ of respondents who had had surgery felt well educated about the procedure, though only $75 \%$ felt they understood their lens and vision options. Three-quarters of those who had had cataract surgery wished they had had the surgery sooner, and reported that they were enjoying life more after surgery.

Conclusion: The ophthalmologist plays an important role in preparing patients for cataract surgery. Discussing both the timing of the surgery and the patient's lens options are critical for appropriate care; the survey results suggest room for improvement in this regard. Respondents reported they wished they had had surgery sooner, based primarily on their improved quality of life postoperatively.

Keywords: cataract surgery, intraocular lens, perception, quality of life

\section{Introduction}

Diagnosing a patient with cataracts is often accompanied by a discussion of the condition and treatment options. The discussion may be primarily directed at educating patients about the actual surgery, and not the results of the surgery. This is especially true if the education to prepare for surgery is focused on obtaining informed consent. Many informed-consent documents focus on the patient's risk understanding as opposed to providing a full picture. ${ }^{1}$ This approach can leave the patient with gaps in their knowledge, which may influence their decisions in undergoing this elective procedure.

A patient's satisfaction with surgical outcomes is associated with preoperative education about options and expected results, as well as with the objective results. ${ }^{2}$ In one study, $65 \%$ of diabetic cataract surgery patients had two Snellen lines of visual acuity improvement, but only $45 \%$ were satisfied with the surgical result, and preoperative
Correspondence: Kerry Solomon

Carolina Eyecare Research Institute,

Carolina Eyecare Physicians,

I I0I Clarity Rd., Suite 100,

Mount Pleasant, SC 29464, USA

Tel +l $84388 \mid 3937$

Fax + I 843375 |487

Email kerry.solomon@carolinaeyecare.com 
education was one causative factor. ${ }^{3}$ Proper preoperative education can be important to setting appropriate expectations, as the expectation-outcome gap is a primary driver of satisfaction with surgical outcomes. ${ }^{3,4}$

Surgeons can sometimes be unaware of the information needs of their patients. ${ }^{5}$ To the surgeon this might be one of many surgeries in the day, but to the patient it may be their first and/or only surgery. The content discussed during the counseling session may be directed at what the doctor finds important as opposed to what the patient values; one study noted that physicians infrequently $(17.8 \%-27.2 \%)$ discussed patient preferences. ${ }^{6}$ This is despite the fact that patients who believed they were actively included in the decision-making process were more satisfied. ${ }^{7,8}$

Patient education ultimately sets the patient's expectation of surgery and should address patient concerns. Healthrelated quality of life is generally higher in patients who perceive their expectations to be met as opposed to those with unmet expectations. ${ }^{4}$ Patients who understood their procedure and the surgical process were more satisfied with the result. ${ }^{9,10}$ Fear, which may be caused by fear of pain and/or complications of surgery, has been associated with anxiety-induced complications, such as uncontrolled hypertension and a higher rate of dissatisfaction. ${ }^{11,12}$ Appropriate preoperative education can mitigate fear. ${ }^{11-13}$

In this age of readily available information and more informed patients, the physician's input is competing with input from a variety of sources. Patients may be acquiring more knowledge from relatives and friends (77\%) as opposed to their physician $(40 \%) .{ }^{14}$ This can result in patient misinformation, with a number of consequences. Expectations may be very low, which may delay a necessary surgery that has the potential for improving quality of life. ${ }^{14}$ Alternatively, expectations may be unrealistically high, contributing to potential postoperative dissatisfaction despite good objective outcomes.

This study utilized a phone survey to determine what patients find important and expect from their cataract surgery, and how the ophthalmologist met those expectations in terms of both preoperative education and patients' satisfaction with postoperative outcomes.

\section{Patients and methods}

A group of experienced cataract surgeons familiar with both common questions from patients presenting for cataract surgery and with new intraocular lens (IOL) technology prepared a list of questions designed to evaluate patient perceptions of the surgery. A set of questions specific to patients who had already had cataract surgery was also prepared. Several rounds of review with a market research firm and the American Association of Retired Persons were conducted to refine the questions and possible responses. A field test was conducted, and a final review resulted in a 117-question survey with an expected completion time of approximately 20 minutes.

The survey was conducted by telephone from February 5 to 16,2013 . Numbers from a random call list were called until 1,000 total respondents were recruited in three specific categories. When a category of respondent was full, no further recruitment took place. All respondents were 50 years of age or older and self-reported never having been considered legally blind. The three specific categories recruited were individuals who had never been diagnosed with cataract and had not had cataract surgery $(n=500)$, individuals who had been diagnosed with cataract but had not had cataract surgery $(n=250)$, and individuals who had had cataract surgery in both eyes in the past 5 years $(n=250)$. Sample-size calculations indicated that the survey margin of error would be $\pm 4.2 \%$ for the first group and $\pm 6.4 \%$ in the second and third groups. For questions common to all groups, the overall margin of error was calculated to be $\pm 3.1 \%$.

A series of screening questions was used to identify appropriate individuals, including questions related to spectacle or contact lens use and general eye health. Participants who passed the screening were asked about their concerns related to vision loss and its possible impact on their quality of life. Data related to their interaction with eye care professionals were collected, with additional questions related to their understanding of vision, the effects of cataracts, and attitudes towards cataract surgery.

Data were tabulated and analyzed using SPSS (version 17.0; SPSS, Chicago, IL, USA) and Statistica (version 12; Dell, Round Rock, TX, USA) Statistical significance was set at $P<0.05$. Responses were categorical, and were tested using the Kruskal-Wallis or Mann-Whitney $U$-test.

The nature of the survey precluded a need for institutional review board approval or registration with clinicaltrials.gov. No protected health information was collected during the survey, so Health Insurance Portability and Accountability Act compliance was not relevant.

\section{Results}

The phone survey was completed by 1,000 respondents in the three categories defined earlier. Table 1 contains the age and sex distributions by group. There were significantly more male respondents in the group without cataracts, but 
Table I Age and sex by survey group

\begin{tabular}{lllll}
\hline & $\begin{array}{l}\text { All } \\
(\mathbf{n = I , 0 0 0 )}\end{array}$ & $\begin{array}{l}\text { Had had surgery } \\
(\mathbf{S}, \mathbf{n = 2 5 0 )}\end{array}$ & $\begin{array}{l}\text { Had cataracts } \\
(\mathbf{C}, \mathbf{n}=\mathbf{2 5 0})\end{array}$ & $\begin{array}{l}\text { No cataracts } \\
\mathbf{( N ,} \mathbf{n = 5 0 0 )}\end{array}$ \\
\hline Male & $31 \%$ & $27 \%$ & $26 \%$ & $37 \% \mathrm{~S}, \mathrm{C}$ \\
Female & $69 \%$ & $73 \% \mathrm{~N}$ & $74 \% \mathrm{~N}$ & $63 \%$ \\
$50-59$ years old & $8 \%$ & $1 \%$ & $3 \%$ & $14 \% \mathrm{~S}, \mathrm{C}$ \\
$60-69$ years old & $31 \%$ & $20 \%$ & $25 \%$ & $40 \% \mathrm{~S}, \mathrm{C}$ \\
$70-79$ years old & $39 \%$ & $44 \% \mathrm{~N}$ & $50 \% \mathrm{~N}$ & $32 \%$ \\
$80+$ years old & $22 \%$ & $35 \% \mathrm{C}, \mathrm{N}$ & $22 \% \mathrm{~N}$ & $15 \%$ \\
\hline
\end{tabular}

Note: Data represent proportion of those significantly higher ( $95 \%$ confidence) than indicated audience (eg, "N", "C" or "S", above).

the majority of the respondents in all three groups were female. Average age was significantly lower in the group without cataracts.

Three-quarters of all respondents reported wearing prescription glasses, with another $17 \%$ using only reading glasses. When asked about specific vision issues besides cataracts, $20 \%$ of respondents who had not had cataract surgery indicated that they had been diagnosed with astigmatism. Astigmatism was the most common vision issue identified. The respondents with cataracts reported more vision issues, even with corrective lenses, relative to those without cataracts and those who had had cataract surgery. The top three visual problems reported for all groups were needing brighter lights to read, nighttime glare/halos, and not seeing clearly at night while driving.

Even with spectacle correction, the respondents with cataracts reported significantly more issues than those who had had surgery or who did not have cataracts. They reported that they needed brighter lights to read ( $48 \%$ versus $27 \%$, $P<0.05)$. They also complained significantly more about nighttime glare/halos (39\% versus $17 \%, P<0.05)$ and night driving $(35 \%$ versus $19 \%, P<0.05)$ relative to those who had had surgery or did not have cataracts.

Despite these difficulties, $61 \%$ of respondents with cataracts believed there were no activities difficult to perform because of vision issues/problems. Forty-four percent of respondents with cataracts reported they were putting off cataract surgery because they believed their vision was "fine for now". Only $38 \%$ planned to have cataract surgery in the next 2 years and $62 \%$ would not have or did not know if they wanted to have cataract surgery.

The respondents in the no-cataract group indicated that they had never been diagnosed with a cataract. However, only $76 \%$ of these respondents believed there were no activities difficult to perform because of vision issues/problems. Eighty-one percent of respondents in this group drove at night, and $26 \%$ of this subgroup noticed glare and halos at night. Reading, using a computer, and driving were the three activities they reported most difficulty performing as a result of their visual problems.
Most of the respondents (71\%) visited an eye care professional at least once per year, regardless of whether or not they had cataracts. However, respondents who did not have cataracts were significantly less likely to see an eye care professional each year than those who had cataracts or those who had already had surgery ( $60 \%$ to $79 \%$ to $84 \%$, respectively; $P<0.05$ ). This is consistent with the observation that only $42 \%$ of respondents who did not have cataracts felt vision was a top health priority, significantly lower than the $55 \%$ of respondents who had cataracts or had had cataract surgery $(P<0.05)$.

Half of the respondents who did not have cataracts reported that an eye care professional had discussed cataracts with them. An ophthalmologist was the most common eye care professional mentioned (71\%), followed by an optometrist (24\%). A significantly higher percentage of respondents who had cataracts had discussed the actual surgery with an eye care professional relative to those without cataracts ( $61 \%$ versus $28 \%, P<0.05$ ). Figure 1 shows the breakdown of the most reported discussion topics. The relative ranking of discussion topics was consistent across the respondent groups. For all respondents, when cataract surgery was discussed, the benefit of the surgery was the most common topic (68\% incidence), followed by a description of the surgery ( $57 \%$ incidence) and recovery from surgery ( $53 \%$ incidence). The incidence of discussing the detailed topics was significantly higher in the group that had had surgery than in the other two groups $(P<0.05)$. For the group that had cataracts but had not had surgery, only $35 \%$ reported that they had discussed the possibility of wearing glasses less often after surgery, and only $23 \%$ reported that different lens options had been discussed. In the group that had had surgery, $75 \%$ of respondents indicated that they had understood their lens and vision options. This difference was statistically significant $(P<0.05)$.

When the respondents with cataracts who had not had surgery were asked why they had not had surgery, there were only three responses with an incidence of greater than 


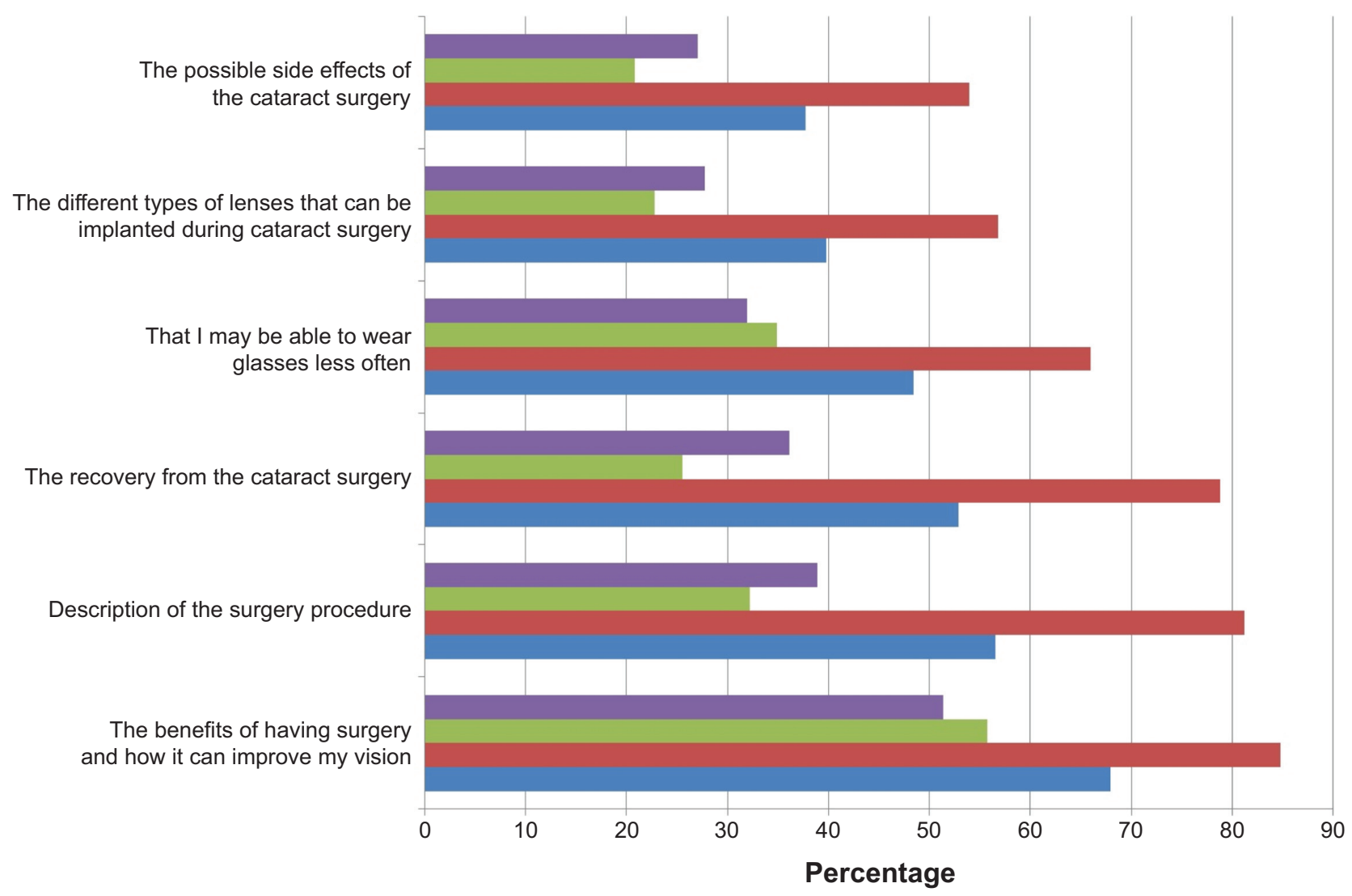

Figure I Most common topics when cataract surgery was discussed with an eye care professional or staff.

Notes: Purple bars represent respondents who did not have cataracts $(n=500)$; green bars represent respondents who had cataracts $(n=250)$; red bars represent respondents who had had cataract surgery $(n=250)$; blue bars represent all respondents $(n=I, 000)$.

$10 \%$; multiple responses were permitted. The most common reason was that the respondents felt their vision was "fine for now" (43\%). The second most common reason was that their doctor had not recommended the surgery (41\%), and the third was that they felt their cataracts were not getting any worse (31\%). When the respondents who had had cataract surgery were asked why they had decided to have surgery, the most common reasons were 1) to improve their vision so that they could see more easily $(81 \%), 2$ ) being advised by a health care professional to have the surgery $(81 \%)$, and 3 ) they did not want their vision to get worse (77\%). A lower percentage of respondents indicated that visual impairment was impacting their daily life (57\%).

A number of questions concerned the expected effects of cataract surgery. Figure 2 shows the vision issues that respondents who had not had surgery believed cataract surgery could improve. The most common responses were improving blurry or foggy vision, improving night vision, and reducing glare and halos. Only about $60 \%$ believed distance vision could be improved or dependence on spectacles could be reduced, and only $50 \%$ believed near vision could be improved. Of those respondents who had had surgery, $85 \%$ reported that cataract surgery helped address all or most of the reasons they elected to have the surgery.

With regard to the actual surgery, the majority of respondents $(84 \%)$ who had had surgery strongly agreed that they were well educated about the procedure. Table 2 contains the percentage of patients who "strongly agreed" with a number of true statements regarding cataract surgery. The level of agreement with these true statements was significantly higher in the group who had had surgery.

The two most important factors identified by respondents in considering whether or not to have cataract surgery were safety and the ability to correct any complications should they arise. Overall, $78 \%$ of respondents strongly agreed "safety of the surgery" was important, and $74 \%$ strongly agreed managing complications was important. Cost, recovery time, and ease of the procedure itself were less important.

The vast majority of respondents $(92 \%)$ reported that maintaining their independence was an important consideration in their quality of life, followed by driving. When considering whether or not to have cataract surgery, a list of activities they might want to perform better was provided; multiple responses were permitted. Figure 3 shows the 


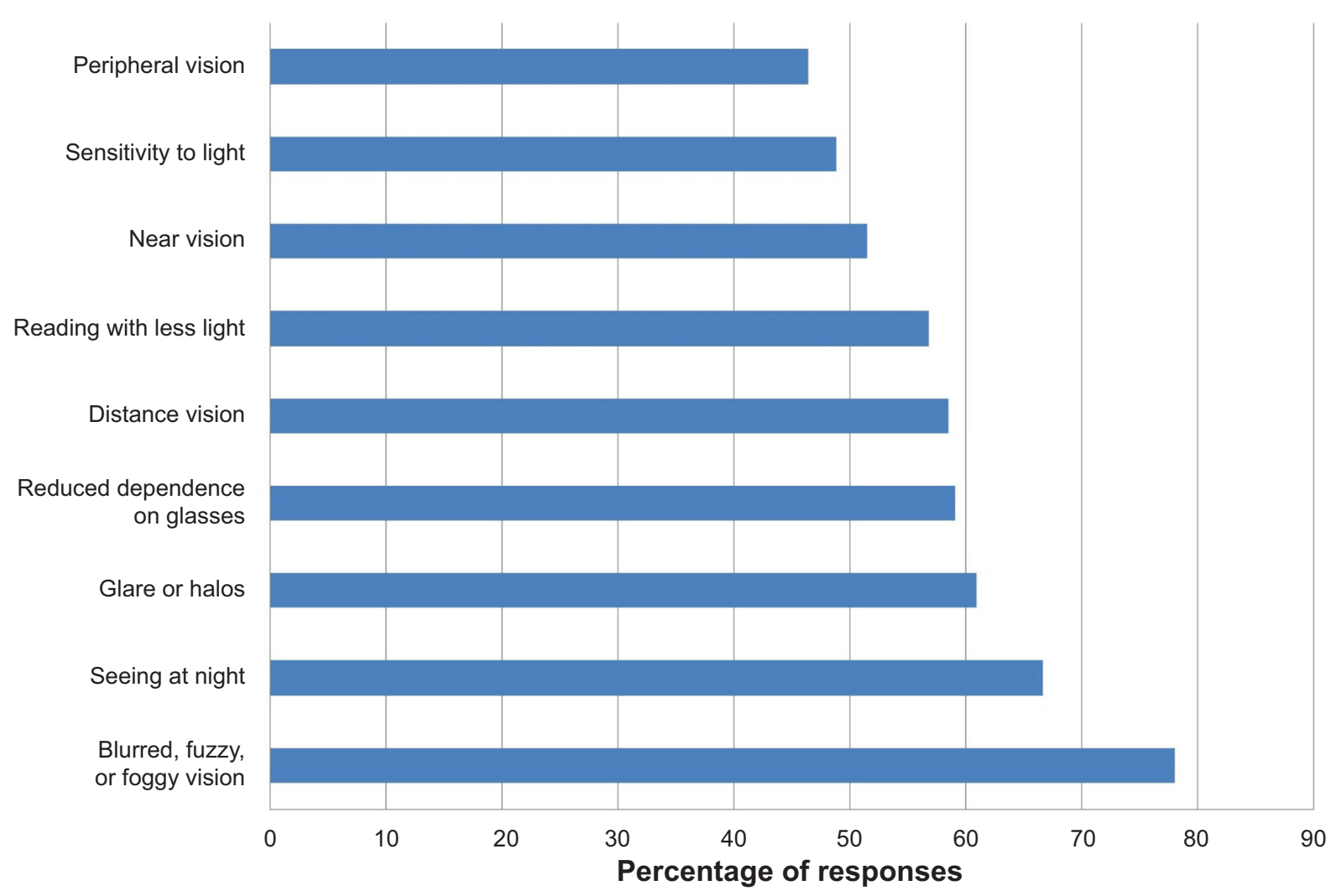

Figure 2 The vision issues that respondents who had not had surgery believed cataract surgery could improve or correct. Note: The number of respondents who had not had surgery was 750 .

highest-ranked activities. Three of the four highest-ranked activities involve near or intermediate work, with the most important distance activity being driving.

The top three reasons patients chose to have cataract surgery were to better enjoy daily activities (75\%), to improve distance visual acuity (61\%), and to improve blurry, fuzzy, and foggy vision $(60 \%)$. In terms of meeting the vision goals of the respondents, $83 \%$ of the group who had had surgery were completely satisfied, and another $8 \%$ were satisfied with their surgery. Eighty-five percent reported that cataract surgery had helped address all or most of the reasons they elected to have the surgery. No respondent reported that they were not at all satisfied with their surgery, and nearly all would definitely recommend (88\%) or recommend (4\%) the surgery to family and friends. Two-thirds reported less dependence on spectacles for distance vision, and $45 \%$ reported less dependence on their reading glasses. Seventy-four percent of those who had had surgery did not think cataract surgery was painful, and $80 \%$ agreed that cataract surgery was easier than expected. Ninety percent did not have side effects or complications that they did not expect. A large number (68\%) of respondents who had had surgery strongly agreed they were surprised at how much their vision improved, and $62 \%$ strongly agreed that they were happy they had cataract surgery and wished they had done it sooner.

Table 2 Percentage of respondents who "strongly agreed" with the given statements, by group

\begin{tabular}{|c|c|c|c|c|c|}
\hline Statement & $\begin{array}{l}\text { All } \\
(n=I, 000)\end{array}$ & $\begin{array}{l}\text { Had cataracts } \\
(C, n=250)\end{array}$ & $\begin{array}{l}\text { No cataracts } \\
(N, n=500)\end{array}$ & $\begin{array}{l}\text { Had had surgery } \\
(\mathrm{S}, \mathrm{n}=\mathbf{2 5 0})\end{array}$ & $\begin{array}{l}P<0.05 \\
(\mathbf{S} \text { to } \mathrm{C}, \mathrm{N}) \\
\end{array}$ \\
\hline Cataract surgery is not painful & 44 & 36 & 34 & 74 & $*$ \\
\hline $\begin{array}{l}\text { Cataract surgery is typically } \\
\text { performed in an hour or two }\end{array}$ & 63 & 60 & 57 & 80 & $*$ \\
\hline $\begin{array}{l}\text { Full range of vision (near, distance, } \\
\text { intermediate) can be corrected } \\
\text { during cataract surgery }\end{array}$ & 46 & 42 & 41 & 59 & $*$ \\
\hline $\begin{array}{l}\text { After cataract surgery, I will not } \\
\text { need to wear my glasses as much }\end{array}$ & 40 & 35 & 36 & 54 & $*$ \\
\hline
\end{tabular}




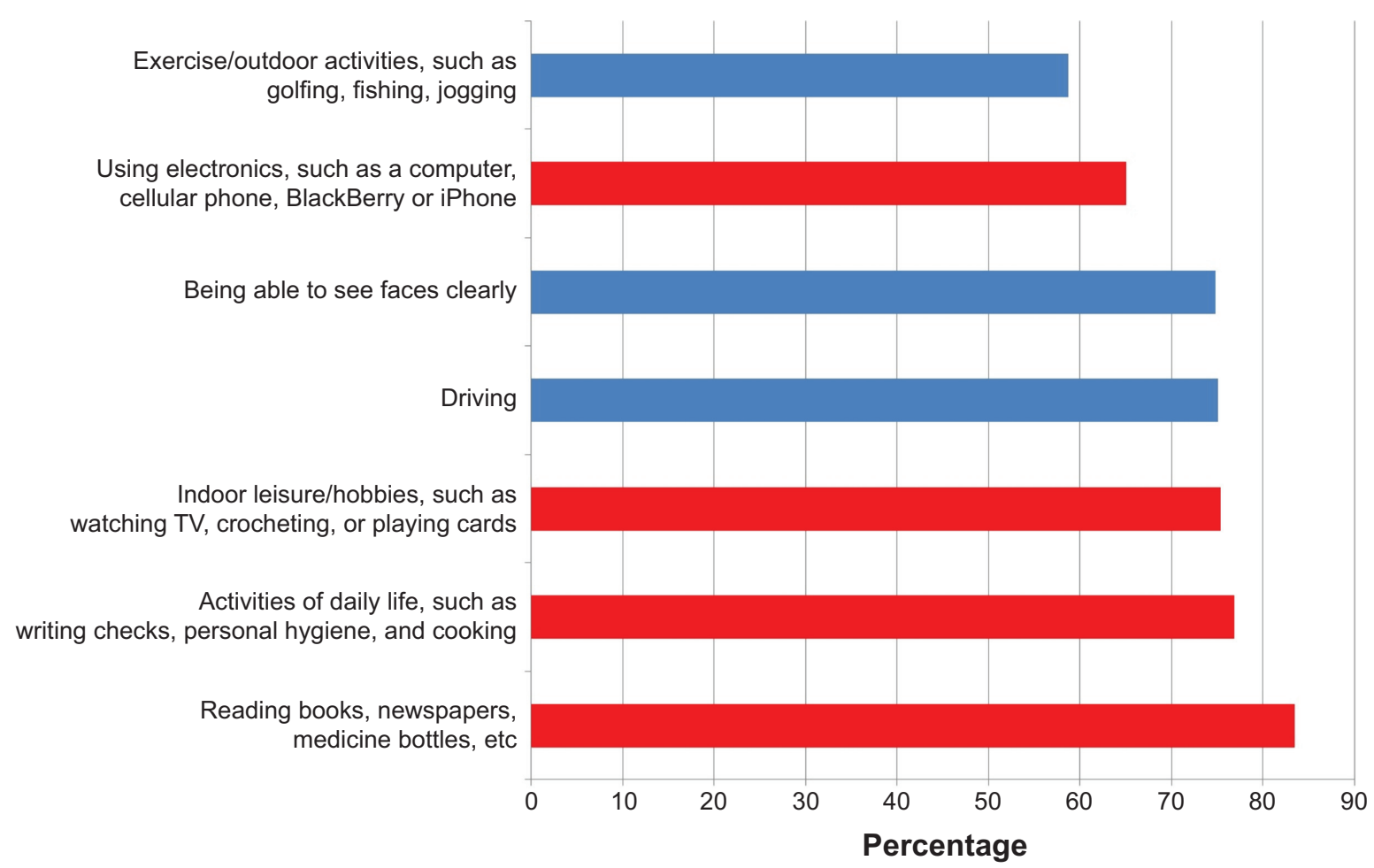

Figure 3 Activities respondents reported that they would like to perform better (with or without glasses) after cataract surgery. Percentage of respondents who felt that improvement in a particular activity was important.

Notes: Red bars represent near/intermediate activities; blue bars represent distance activities.

\section{Discussion}

It is clear from these results, and not entirely surprising, that the ophthalmologist plays an important role both at the time of cataract surgery and during the decision phase preceding surgery. The majority of respondents indicated that they had discussed cataract surgery with an ophthalmologist. The decision related to surgery is highly dependent on these discussions, with four of five respondents indicating a surgeon's recommendation was the reason they went ahead with surgery. This is in agreement with a previous study where $61 \%$ of patients preferred a physician-dominated decision. ${ }^{15}$ This heavy reliance on the physician's recommendation must be balanced with the importance of patient involvement in decision making, which is believed to result in more satisfaction with surgical outcomes. ${ }^{7,8}$

In the current survey, two in five of the respondents who had not had surgery indicated that their eye doctor's recommendation was one of the reasons. This is despite the fact that a quarter of respondents who reported not having been diagnosed with cataracts reported difficulty with glare and halos. It may be that the criteria for diagnosing cataracts are inappropriate. In the past, a loss of several lines of high-contrast acuity might have been considered an appropriate indicator of significant cataract. However, a more recent diagnostic paradigm is the loss of visual function that interferes with normal activities, such as having difficulty driving at night. More appropriate diagnosis of cataracts includes contrast-sensitivity testing, glare testing, or questioning the patient regarding the effects of vision on their lifestyle. There have been a number of recent efforts to improve the ability to detect significant effects of cataract before changes in high-contrast acuity are noted. ${ }^{16,17}$ Earlier treatment of cataracts has shown significant benefits in terms of both patient safety and quality of life. . $^{18,19}$

Table 2 is of interest in terms of the effect of education. It appears that surgeon communication at the time of surgery has a significant effect on the percentage of patients who understood the nature of cataract surgery. The last two items listed are of interest. The patients who had had surgery were significantly more likely to agree strongly with the fact that they could have a full range of vision restored (59\% versus $42 \%, P<0.05$ ), and that they were likely to depend on spectacles less ( $54 \%$ versus $36 \%, P<0.05$ ). While these responses appear to have been significantly improved by education at the time of surgery, the final percentages $(59 \%$ and $54 \%$, respectively) appear relatively low. Improved patient education might be helpful in those two areas.

There was a dichotomy in terms of respondents' indication of their understanding of lens options. Fewer than 
$25 \%$ of respondents with cataracts report having discussed different lens options with an eye care professional, and only $55 \%$ of the group who had had surgery reported discussing this topic. However, $75 \%$ of those respondents who had had surgery report that they understood the extent of their lens and vision correction options prior to surgery. This suggests that a high percentage of patients may have presumed they understood their lens/vision options, though the issue may not have been specifically discussed. It would appear that more discussion of the various lens options, particularly with regard to advanced-technology IOLs, such as toric IOLs or presbyopia-correcting IOLs, might be warranted. The discussion of toric IOLs is important given the desire of a majority of respondents to rely on their glasses less for distance vision, though many respondents indicated that they know they had astigmatism. The discussion of presbyopia-correcting IOLs is particularly important, because a high percentage of patients indicated near tasks were among the activities they would most like to be improved after cataract surgery.

One of the areas in which the surgeon can help bridge a knowledge gap is surgical misconceptions that affect the patient from making a well-informed decision. This includes misconceptions of fear, such as fear of pain or fear of unexpected complications during surgery. Such fear may cause patients to put off having cataract surgery longer than they should. More patient education for those with cataracts who may be facing surgery in the near future might be appropriate, to allay these fears early in the process.

Related to the point just mentioned is the fact that earlier education may also be warranted regarding the effects of cataracts and the potential benefits of surgery. Only $76 \%$ of respondents in the group that had not been diagnosed with cataracts stated that they had no vision issues (indicating $24 \%$ had one or more issues), and a quarter of the drivers in that group reported noticing glare and halos. Almost half the respondents in the group with cataracts felt their vision was "fine for now". The gradual deterioration of vision with cataracts may make it difficult for patients to appreciate changes. Ophthalmologists can address this by discussing any loss of functional vision with patients, and determining if cataracts are the cause. This may assist patients in recognizing the effects of cataracts much earlier. This has a significant potential benefit, as $68 \%$ of the patients who had had surgery strongly agreed that they were surprised by how much their vision improved, and $62 \%$ indicated they wished they had opted for cataract surgery sooner.

The content of the preoperative counseling discussion is important in shaping postoperative satisfaction with surgical outcomes. Consistent with the findings here, earlier studies indicate that patients mostly value understanding the complication rate of surgical intervention ${ }^{20}$ and the likely extent of visual improvement. ${ }^{21}$ Ophthalmologists might address the former by noting the significant reduction in complication rates with modern phacoemulsification, and the latter through highlighting the excellent refractive results possible with modern biometric formulae and diagnostic instruments.

There are limitations to the findings reported here. As with all surveys, there was a heavy reliance on patient recall. Patients' memories of surgical events are known to deteriorate with time, ${ }^{22}$ and the respondents in this survey were asked about surgery they had had up to 5 years ago. Even those who had not had surgery were asked to recall past interactions with their eye care professional.

In conclusion, patients rely heavily on their physicians' recommendations to undergo cataract surgery. The majority of respondents indicated that they visit their eye doctors frequently. This provides an opportunity for the ophthalmologist to discuss the changes in visual function that may occur with cataracts. Although cataracts may not affect their visual acuity, they may be affecting the patient's quality of life. The safety of modern cataract surgery and the improvement in visual function possible should also be discussed, including the potential visual outcomes with advanced-technology IOLs, such as toric and presbyopia-correcting IOLs. The earlier this discussion takes place, the more time the patient will have to monitor the changes to their vision caused by their advancing cataracts, and to consider their IOL options.

\section{Acknowledgment}

Sarah Y Makari, OD is a consultant to Science in Vision who received compensation for writing assistance in the preparation of the initial manuscript draft.

\section{Disclosure}

Financial support for this study was provided by Alcon, Fort Worth, TX. The sponsor participated in the design of the study, conducting the study, data collection, data management, and review of the manuscript for technical accuracy. The sponsor provided funding for data analysis and manuscript preparation. The sponsor was not involved in the analysis of the data or preparation of the manuscript. All authors have a consulting relationship with Alcon. No author has a financial interest in the material presented here. Other aspects of the survey described here have been submitted for publication elsewhere, but no submitted manuscripts to date 
have been accepted or published. The results presented and discussed here have not been reported elsewhere.

\section{References}

1. Schenker Y, Fernandez A, Sudore R, Schillinger D. Interventions to improve patient comprehension in informed consent for medical and surgical procedures: a systematic review. Med Decis Making. 2011; 31(1):151-173.

2. Nijkamp MD, Nuijts RM, Borne B, Webers CA, van der Horst F, Hendrikse F. Determinants of patient satisfaction after cataract surgery in 3 settings. J Cataract Refract Surg. 2000;26(9):1379-1388.

3. Mozaffarieh M, Krepler K, Heinzl H, Sacu S, Wedrich A. Visual function, quality of life and patient satisfaction after ophthalmic surgery: a comparative study. Ophthalmologica. 2004;218(1):26-30.

4. Pusic AL, Klassen AF, Snell L, et al. Measuring and managing patient expectations for breast reconstruction: impact on quality of life and patient satisfaction. Expert Rev Pharmacoecon Outcomes Res. 2012; 12(2):149-158.

5. Mulsow JJ, Feeley TM, Tierney S. Beyond consent - improving understanding in surgical patients. Am J Surg. 2012;203(1):112-120.

6. Braddock CH 3rd, Edwards KA, Hasenberg NM, Laidley TL, Levinson W. Informed decision making in outpatient practice: time to get back to basics. JAMA. 1999;282(24):2313-2320.

7. Berg A, Yuval D, Ivancovsky M, Zalcberg S, Dubani A, Benbassat J. Patient perception of involvement in medical care during labor and delivery. Isr Med Assoc J. 2001;3(5):352-356.

8. Janz NK, Wren PA, Copeland LA, Lowery JC, Goldfarb SL, Wilkins EG. Patient-physician concordance: preferences, perceptions, and factors influencing the breast cancer surgical decision. J Clin Oncol. 2004; 22(15):3091-3098.

9. Pager CK. Randomised controlled trial of pre-operative information to improve satisfaction with cataract surgery. Br J Ophthalmol. 2005; 89(1):10-13.

10. Pager CK. Expectations and outcomes in cataract surgery: a prospective test of 2 models of satisfaction. Arch Ophthalmol. 2004;122(12): $1788-1792$.

11. Nijkamp MD, Ruiter RA, Roeling M, et al. Factors related to fear in patients undergoing cataract surgery: a qualitative study focusing on factors associated with fear and reassurance among patients who need to undergo cataract surgery. Patient Educ Couns. 2002;47(3):265-272.
12. Voon LW, Au Eong KG, Saw SM, Verma D, Laude A. Effect of preoperative counseling on patient fear from the visual experience during phacoemulsification under topical anesthesia: multicenter randomized clinical trial. J Cataract Refract Surg. 2005;31(10):1966-1969.

13. Ang CL, Au Eong KG, Lee SS, Chan SP, Tan CS. Patients' expectation and experience of visual sensations during phacoemulsification under topical anaesthesia. Eye (Lond). 2007;21(9):1162-1167.

14. Cheung KW, Chung SL, Chung KY, Chiu KH. Patient perception and knowledge on total joint replacement surgery. Hong Kong Med J. 2013;19(1):33-37.

15. Kiss CG, Richter-Mueksch S, Stifter E, Diendorfer-Radner G, VelikayParel M, Radner W. Informed consent and decision making by cataract patients. Arch Ophthalmol. 2004;122(1):94-98.

16. Ni W, Li X, Ao M, et al. Using the real-life vision test to assess the functional vision of age-related cataract patients. Eye (Lond). 2012;26(11): 1402-1411.

17. Babizhayev MA, Minasyan H, Richer SP. Cataract halos: a driving hazard in aging populations. Implication of the Halometer DG test for assessment of intraocular light scatter. Appl Ergon. 2009;40(3): 545-553.

18. Fong CS, Mitchell P, Rochtchina E, Teber ET, Hong T, Wang JJ. Correction of visual impairment by cataract surgery and improved survival in older persons: the Blue Mountains Eye Study cohort. Ophthalmology. 2013;120(9):1720-1727.

19. Lee JE, Fos PJ, Sung JH, et al. Relationship of cataract symptoms of preoperative patients and vision-related quality of life. Qual Life Res. 2005; 14(8):1845-1853.

20. Ross MA, Avery AJ, Foss AJ. Views of older people on cataract surgery options: an assessment of preferences by conjoint analysis. Qual Saf Health Care. 2003;12(1):13-17.

21. Elder MJ, Suter A. What patients want to know before they have cataract surgery. Br J Ophthalmol. 2004;88(3):331-332.

22. Scanlan D, Siddiqui F, Perry G, Hutnik CM. Informed consent for cataract surgery: what patients do and do not understand. $J$ Cataract Refract Surg. 2003;29(10):1904-1912.
Clinical Ophthalmology

\section{Publish your work in this journal}

Clinical Ophthalmology is an international, peer-reviewed journal covering all subspecialties within ophthalmology. Key topics include: Optometry; Visual science; Pharmacology and drug therapy in eye diseases; Basic Sciences; Primary and Secondary eye care; Patient Safety and Quality of Care Improvements. This journal is indexed on

\section{Dovepress}

PubMed Central and CAS, and is the official journal of The Society of Clinical Ophthalmology (SCO). The manuscript management system is completely online and includes a very quick and fair peer-review system, which is all easy to use. Visit http://www.dovepress.com/ testimonials.php to read real quotes from published authors. 